\title{
THE STUDY OF CORRELATION BETWEEN LEIDEN V FACTOR AND METHYLEN TETRAHYDROFOLATE REDUCTASE ENZYME GENE MUTATIONS IN PRIMIGRAVIDA WITH MISSED
}

ABORTION IN LATE FIRST TRIMESTER

Nermeen Saad Elbeltagy, Mohamed Mostafa Mohamed Rizk*, Nermeen Mohamed Hefila, Doaa Elzoghabi Mohamed Hassen Department of Obstetrics and Gynecology, Department of Clinical and Chemical Pathology*, Faculty of Medicine, Alexandria University, Egypt.

\section{INTRODUCTION}

Pregnancy is a hypercoagulable state secondary to an increase in coagulation factors, a reduction in naturally occurring anticoagulants, and impairment of fibrinolysis.

Pregnancy losses were divided into preclinical, first trimester clinical, and second trimester. A meaningfully increased rate of preclinical pregnancy failure in Leiden mutation carriers was found than in no activated protein $\mathrm{C}$ deficiency patients.

Another cause of miscarriages is inherited thrombophilia following damage to the maternal factor V gene G1691A (Leiden mutation) and prothrombin gene (G20210A mutation). These alterations are well studied and the test is part of the routine diagnostics of recurrent mis carriages. In the case of factor V, both the Leiden mutation G1691A and the T1328C mutatio . week of gestation.

The most common causes of inherited thrombophilia are polymorphisms in genes encoding while protein $C$, protein $S$ and ant thrombin deficiency is less common.

The finding of a link between FVL carrier state and early RPL would have significant implications for clinical practice, as it would provide a scientific rationale for screening for FVL mutation and targeted thrombo prophylaxis in affected women.

\section{AIM OF THE WORK}

This work aimed to evaluate the correlation of factor $\mathrm{V}$ Leiden $(\mathrm{FVL})$ and methylenetetrahydrofolate reductase (MTHFR) C677T gene mutation with missed abortion in primigravida in the late first trimester to identify candidates for anticoagulation therapy to improve pregnancy outcome.

\section{SUBJECTS AND METHODS}

The present study was across-sectional study conducted on 40 primigravida females recruited from EL Shatby hospital. All participating women were primigravida in their ate first trimester with missed abortion. Blood samples were collected from all pregnan women enrolled in the study for DNA extraction and genotype analysis based on polymerase chain reaction and reverse hybridization. The two mutations covered by the study are the FVL, and MTHFR C667T.

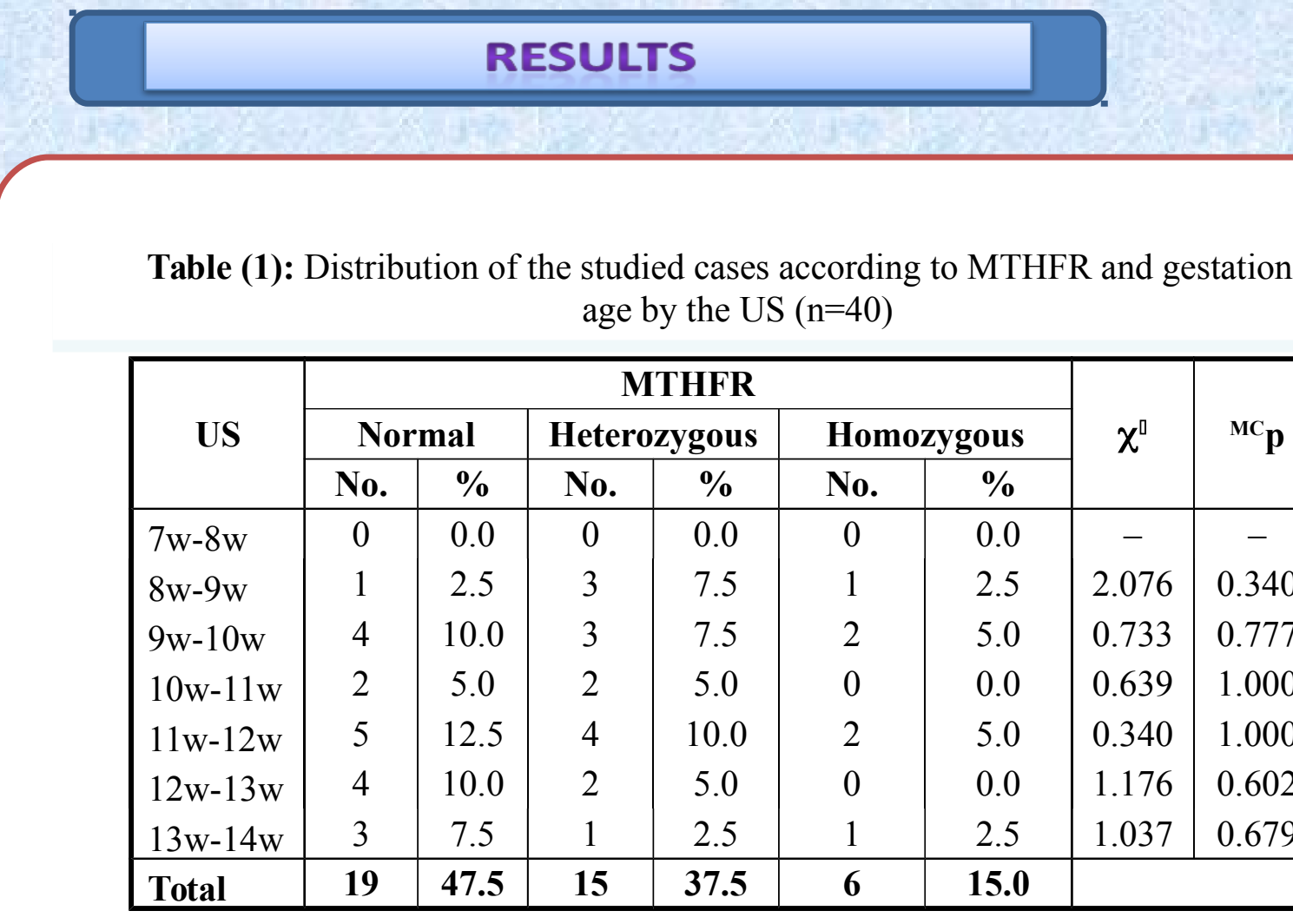

$\chi^{2}$ : Chi-square tes

MC: Monte Carlo

$p$ : $p$-value for comparing between the three categories

Table (2): Distribution of the studied cases according to factor V Leiden $(\mathrm{n}=40)$

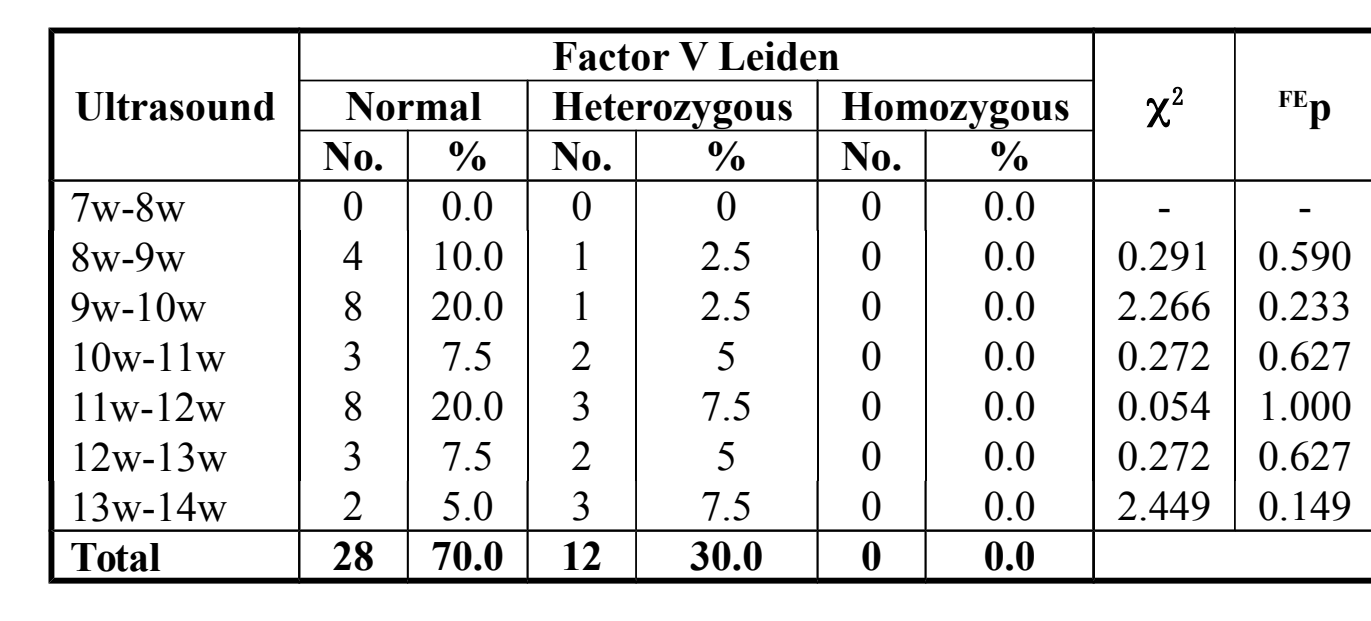

$\chi^{2}$ : Chi-square test

FE: Fisher Exact

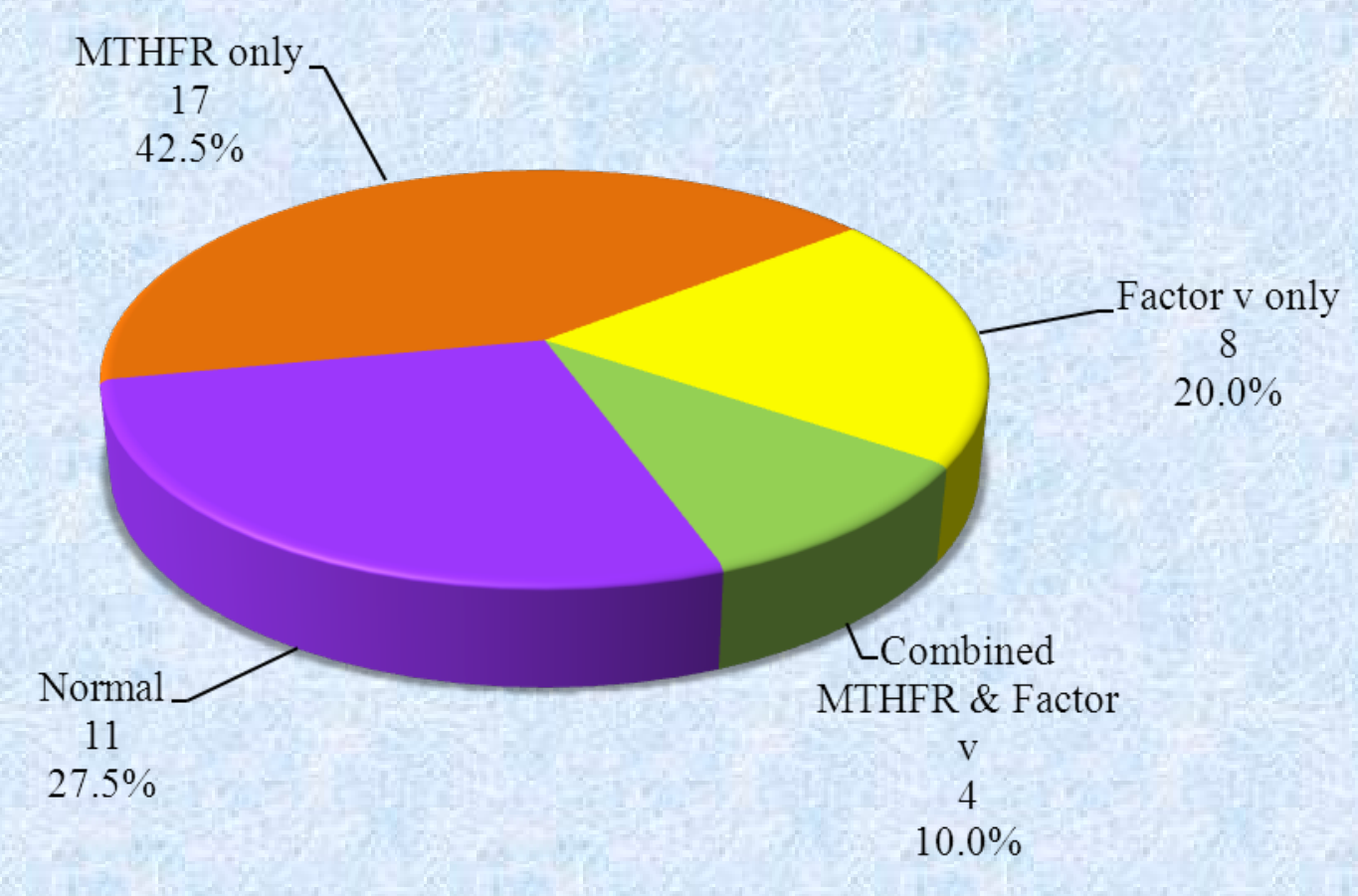

Figure: Distribution of the studied cases according to MTHF \& factor $\mathrm{V}(\mathrm{n}=40)$

\section{CONCLUSION}

The prevalence of FVL mutations in our study did not appear significantly affect abortion in primigravida. MTHFR C667T mutations prevalence were appeared significantly have a relation to abortion. 